\title{
Acquired epidermolysis bullosa
}

INSERM

\section{Source}

INSERM. (1999). Orphanet: an online rare disease and orphan drug data base. Acquired epidermolysis bullosa. ORPHA:46487

Epidermolysis bullosa acquisita (EBA) is a subepidermal bullous dermatosis of autoimmune orig in that was named as a result of its resemblance to hereditary forms of epidermolysis bullosa (HEB), most notably dystrophic HEB. 